\title{
Pricing Mining Concessions Based on Combined Multinomial Pricing Model
}

\author{
Chang Xiao and Jinsheng Zhou \\ School of Humanities and Economic Management, China University of Geosciences, Beijing 100083, China \\ Correspondence should be addressed to Chang Xiao; 3007150021@cugb.edu.cn
}

Received 16 October 2016; Revised 5 December 2016; Accepted 21 December 2016; Published 18 January 2017

Academic Editor: Ricardo López-Ruiz

Copyright (c) 2017 Chang Xiao and Jinsheng Zhou. This is an open access article distributed under the Creative Commons Attribution License, which permits unrestricted use, distribution, and reproduction in any medium, provided the original work is properly cited.

\begin{abstract}
A combined multinomial pricing model is proposed for pricing mining concession in which the annualized volatility of the price of mineral products follows a multinomial distribution. First, a combined multinomial pricing model is proposed which consists of binomial pricing models calculated according to different volatility values. Second, a method is provided to calculate the annualized volatility and the distribution. Third, the value of convenience yields is calculated based on the relationship between the futures price and the spot price. The notion of convenience yields is used to adjust our model as well. Based on an empirical study of a Chinese copper mine concession, we verify that our model is easy to use and better than the model with constant volatility when considering the changing annualized volatility of the price of the mineral product.
\end{abstract}

\section{Introduction}

It is very important for a mining company to set reasonable prices for mining concessions. In China, mining resources belong to the state. To conduct mining operation, a mining company must first purchase the mining concession. In addition, a mining company can profit from transferring mining concessions that they have purchased. Mining concession's appreciation can have a favorable impact on the valuation of the mining company. A relatively large error in the estimation of the price of the mining concession during the evaluation step can result in a loss of the company's economic benefits.

Decision tree pricing models represent a method of option pricing models. One of these decision tree pricing models, the binomial pricing model, was first proposed by Cox et al. [1]. Later, numerous researchers contributed to binomial pricing models' evolution to a multinomial pricing model. Some researchers have conducted both theoretical and empirical studies on the multinomial pricing model. All of these studies have demonstrated that the multinomial pricing model is suitable for option pricing and can be used to obtain an option price that is close to the market price [2-4].

Because a mining concession has the characteristics of a real option, a decision tree pricing model can be used to price a mining concession. When using traditional decision tree pricing models to price mining concessions, it is of particular importance to determine the price volatility of the mineral product, which is a key variable of this model. When calculating the price of the mining concession of an offshore oil field in the Netherlands, Smit first calculates six-year annualized volatility of the price of Brent crude oil between 1988 and 1993. Then, he determines the annualized volatility based on the annualized volatility values of the previous two years and mean annualized volatility of all six years [5]. $\mathrm{Gu}$ et al. calculate monthly volatility based on the historical data and assume that the monthly volatility of each of the following months remained the same [6]. The aforementioned studies both assume that volatility was a constant and make their calculations based on this assumption. However, some researchers believe that the use of constant volatility will result in overestimation or underestimation of the price of a mining concession because volatility can experience relatively significant variations from year to year. Therefore, it is more reasonable to assume that the volatility is stochastic (e.g., Ting et al. [7] and Huang et al. [8]). However, models based on this assumption are relatively complex and therefore have rarely been used in practice. One of the reasons, which causes the model to be complex to use, is the distribution 
assumption of the annualized volatility of the price of mineral products.

Some researchers have studied the distribution of the volatility of the price of underlying assets. For example, Liesenfeld and Jung believe that the volatility of stock prices closely approximates a $t$-distribution [9]. Andersen et al. studied the volatility of foreign exchange rates and stocks return, discovering that both of them approximate a lognormal distribution with a sharp peak and a right-skewed feature $[10,11]$. The calculation of the distribution feature of the price volatility in the aforementioned studies is both relatively complicated and relatively difficult to carry out in practice. Therefore, some researchers assume that the volatility of the price of underlying assets follows a multinomial distribution and use multinomial pricing model to price options (e.g., Madan et al. [12] and Florescu and Viens [13]). However, it is also difficult to calculate the price of mining concession if we use multinomial pricing model directly.

In addition, because the owner of a mining concession can obtain spot mineral product by mining, convenience yield must be taken into consideration when calculating the price of the mining concession. Since the concept of convenience yield was introduced by Kaldor [14], numerous researchers have studied the relationship between the futures price and the spot price based on the convenience yield. Lin and Duan estimate the change in the convenience yield under the impact of supply and demand, finding that the convenience yield exhibits seasonal characteristics; that is, the convenience yield decreases in seasons when there is a strong demand and increases in seasons when there is a low demand [15]. By using the convenience yield as the indicator of the supply risk, Stepanek et al. find correlations between the convenience yield and the static inventory of stock on the one hand and the future spot price on the other hand [16].

In this study, because the assumption of constant volatility has its defects and the assumption of stochastic volatility is complex to calculate, we assume that the annualized volatility of the price of mineral products follows a multinomial distribution. In order to take into consideration the notion that the annualized volatility of the price of mineral products may experience relatively significant variations from year to year, we propose a combined multinomial pricing model for pricing mining concessions. The combined multinomial pricing model is obtained as follows: first, calculate the distribution series of the annualized volatility of the price of the mineral product through grouped statistical analysis; then, different values of the annualized volatility are calculated based on binomial pricing models; finally, these binomial models are combined into a multinomial pricing model based on the probability corresponding to each value of the annualized volatility values. This study's empirical research demonstrates that the combined multinomial pricing model considers the high and low annualized volatility simultaneously. Therefore, this model is more practical.

The rest of the paper is structured as follows. Section 2 introduces traditional decision tree models and focuses on binomial and multinomial pricing models. Section 3 elucidates the pricing method and combined multinomial pricing model used in this study. Section 4 describes an empirical study of a copper mine in China, including the calculation result. Section 5 compares the combined multinomial pricing model with previously known work. Section 6 provides this study's conclusions.

\section{Traditional Decision Tree Model}

Ever since a binomial option pricing model (CRR model) was first proposed by Cox et al. [1], decision tree pricing models have been widely used. Over the years, other researchers have popularized the CRR model. The scope of application of decision tree models not only has widened but also has been expanded from binomial and trinomial models to multinomial pricing models.

Decision tree pricing models were initially used to price financial options and were later used to price real options. Because mining concession is a type of tradable right and a type of real option, decision tree pricing models can be used to price a mining concession. When using a decision tree pricing model to price a mining concession, the variables are often defined as follows:

$S$ : value of the mine

$X$ : cost of the mine

$T$ : the time to expiration of the mining concession

$\sigma$ : volatility of the price of the mineral product

$r$ : risk-free interest rate

2.1. Binomial Pricing Model. Cox et al. derive a binomial option pricing model using the portfolio replication and risk-neutral approaches [1]. When calculating the value of a mining concession using the binomial approach, we assume that the value of the mine equals the product of the price of the mineral product and the reserve of the mineral product. Therefore, it is necessary to determine the extent of the increase and decrease in the value of the mine in each period of time based on the volatility of the price of the mineral product and establish a corresponding tree diagram of the variation of the value of the mine. Ultimately, calculate the price of the mining concession through reverse deduction based on the tree diagram.

The calculation process of a one-step binomial pricing model is as follows:

$$
\begin{aligned}
u & =e^{\sigma \sqrt{T}}, \\
d & =e^{-\sigma \sqrt{T}} \\
p & =\frac{e^{r T}-d}{u-d} \\
f_{u} & =\max (0, S u-X) \\
f_{d} & =\max (0, S d-X) \\
f_{0} & =e^{-r T}\left[p f_{u}+(1-p) f_{d}\right],
\end{aligned}
$$

where $T$ represents the time to expiration of the mining concession; $\sigma$ represents the annualized volatility of the price 
of the mineral product; $u$ represents the upstream multiplier of the value of the mine; $d$ represents the downstream multiplier of the value of the mine; $f_{u}$ represents the price of the mining concession after it increases; $f_{d}$ represents the price of the mining concession after it decreases; $p$ represents the probability that the value of the mine will rise; $f_{0}$ represents the price of the mining concession at the current time, that is, the price of the mining concession; $r$ represents the risk-free interest rate; $S$ represents the value of the mine at the current time; and $X$ represents the cost of the mine.

If the time to expiration of the mining concession $(T)$ is divided into $n$ number of periods of time, a multistep binomial pricing model can be obtained by further derivation. The expressions of multistep binomial pricing model are as follows:

$$
\begin{aligned}
f_{u^{i} d^{n-i}} & =\max \left(0, S u^{i} d^{n-i}-X\right) \\
f_{0} & =e^{-r T}\left[\sum_{i=0}^{n}\left(\begin{array}{l}
i \\
n
\end{array}\right) p^{i}(1-p)^{n-i} f_{u^{i} d^{n-i}}\right],
\end{aligned}
$$

where $i$ represents the number of times that the value of the mine increases; $f_{u^{i} d^{n-i}}$ represents the price of the mining concession after the value of the mine increases $i$ number of times and decreases $n-i$ number of times, that is, the price of the option when the mining concession expires (there are $n+1$ possibilities); and the meaning of each of the remaining variables is the same as that in the one-step binomial-tree model.

2.2. Multinomial Pricing Model. The calculation process of the multinomial pricing model is established based on the popularization of the binomial pricing model. Cox et al. argue that the price of an option is the mathematical expectation of the discount value of the option at expiration [1]. It is the same with mining concessions.

We assume that a one-step multinomial tree has $m$ number of branches; that is, there are $m$ possible variations of the value of the mine at the end of the period of time. If $f_{0}$ is the price of the mining concession at the current time and $S$ is the value of the mine at the current time, after the $i$ th $(1 \leq i \leq m, i \in \mathrm{N})$ type of price change, the price of the mining concession changes from $f_{0}$ to $f_{i}$ and the value of the mine changes from $S$ to $S b_{i}$, that is, $b_{i}$ number of times the value of the mine at the current time. Based on the assumptions mentioned above, the expressions of the onestep multinomial pricing model are obtained as follows:

$$
\begin{aligned}
& f_{i}=\max \left(0, S b_{i}-X\right) \\
& f_{0}=e^{-r T} \sum_{i=1}^{m} p_{i} f_{i} \quad(m \geq 2, m \in N),
\end{aligned}
$$

where $p_{i}$ represents the probability that the price of the mining concession will change from $f_{0}$ to $f_{i}$; $T$ represents the time to expiration of the mining concession; $r$ represents the risk-free interest rate; and $X$ represents the cost of the mine.

Similar to the binomial and trinomial pricing models, if the time to expiration of the mining concession $(T)$ is divided into $n$ number of periods of time, a multistep multinomial pricing model can be obtained by further derivation. Its expressions are as follows:

$$
\begin{aligned}
& f_{b_{1}{ }^{k_{1}} b_{2}{ }_{2} \ldots b_{m}{ }^{k_{m}}}=\max \left(0, S \prod_{i=1}^{m} b_{i}^{k_{i}}-X\right) \\
& f_{0}=e^{-r T}\left(\sum_{k_{1}+k_{2}+\cdots+k_{m}=n} \frac{n !}{\prod_{i=1}^{m} k_{i} !} p_{1}{ }^{k_{1}} p_{2}{ }^{k_{2}}\right. \\
& \left.\cdots p_{m}{ }^{{ }^{k}} f_{b_{1}{ }^{k_{1}} b_{2}{ }^{k_{2} \ldots b_{m}}}{ }^{{ }^{m}}\right)
\end{aligned}
$$

where $k_{i}$ represents the number of times that the value of the mine undergoes the $i$ th type of price change; $f_{b_{1}}{ }_{1} b_{2}{ }^{{ }_{2} \ldots . . b_{m}}{ }^{{ }}{ }_{m}$ represents the price of the mining concession after the value of the mine undergoes $k_{1}$ number of times of the first type of change, $k_{2}$ number of times of the second type of change,..., $k_{m}$ number of times of the $m$ th type of change, that is, the price of the mining concession when it expires; and the meaning of each of the remaining variables is the same as that in the one-step multinomial pricing model.

For the multistep multinomial pricing model, the calculation of $p_{i}$ is very complicated by algebraic methods. Consequently, most of the studies have not used the multistep multinomial pricing model when pricing mining concessions. Some researchers attempt to solve this problem. For example, Cox and Rubinstein obtain the relationship between the probability of continuous stock trading and the present value selected in a chance event by introducing a complex option and then obtaining the variation probability through reverse derivation by the use of other variables [17]. To obtain a simpler expression when using the prospect theory proposed by Rockenbach [18], Yan takes the reciprocal of the number of branches of the multistep multinomial pricing model for the probabilities of each type of price change [19].

\section{Pricing Method and Model}

3.1. Calculation of Annualized Volatility. When using a decision tree pricing model to price a mining concession, it is necessary to calculate the annualized volatility of the price of the mineral product. Based on the book of Hull [20], the process of calculating the annualized volatility of the price of the mineral product is as follows.

First, the daily yield needs to be calculated, which is expressed in the logarithmic form:

$$
R_{i}=\ln \frac{S_{i}}{S_{i-1}},
$$

where $R_{i}$ represents the yield on the $i$ th day and $S_{i}$ represents the price of the mineral product on the $i$ th day.

Next, the standard deviation, $s$, of the daily yield is calculated:

$$
s=\sqrt{\frac{1}{n_{y}-1} \sum_{i=1}^{n}\left(R_{i}-\bar{R}\right)^{2}},
$$


where $n_{y}$ represents the number of days in a year on which spot trading of the mineral product occurs $\left(n_{y}\right.$ is usually set to 250 ) and $\bar{R}$ represents the $n$ number-of-day average daily yield.

Finally, the daily standard deviation is converted to an annual standard deviation, that is, the annualized volatility, $\sigma:$

$$
\sigma=s \sqrt{n_{y}}
$$

3.2. Calculation of Distribution. In some complex models, the annualized volatility of the price of mineral products follows a log-normal distribution or Student's $t$-distribution. To simplify the calculation process, this study assumes that the annualized volatility of the price of a mineral product follows a multinomial distribution. Under this assumption, each of the previous years' annualized volatility values of the price of a mineral product is mutually independent and can only take a limited number of values. In addition, the probability that the annualized volatility has each of the aforementioned values is fixed.

Based on the efficient markets hypothesis, the annualized volatility values of the price of a mineral product are mutually independent. Moreover, the annualized volatility of the price of mineral products has mean-reversion characteristics. Therefore, the volatility fluctuates within a certain range most of the time. Here, copper is taken as an example. Based on the study conducted by Figuerola-Ferretti and Gilbert, the monthly volatility of the spot price of copper between October 3, 1982, and December 30, 2005, was less than $70 \%$ and fluctuated around $25 \%$ [21]. The same was true for the annualized volatility. Therefore, we can calculate the distribution by using the grouped statistical analysis method. In reality, according to the central-limit theorem, the limits of a multinomial distribution follow a normal distribution. Therefore, if a multistep decision tree pricing model is used, the price of a mining concession priced based on the multinomial distribution assumption will be close to the price of the mining concession priced based on the normal distribution assumption.

After the annualized volatility of the price of the mineral product of each of the previous years is obtained, the distribution series of the annualized volatility of the price of the mineral product can be approximated using the grouped statistical analysis method based on the assumption that the annualized volatility of the price of the mineral product follows a multinomial distribution.

To conduct a grouped statistical analysis of the annualized volatility of the spot price of copper, it is necessary to first calculate the annualized volatility of the spot price of copper of each year over the course of $n$ number of years and then conduct a grouped statistical analysis of the annualized volatility (each group has a span of $10 \%$ ). There are seven groups overall. Table 1 lists the statistical results.

Through the grouped statistical analysis of the annualized volatility, $a_{i} / n$ can be approximately considered the probability of the annualized volatility of the price of the mineral product said to be within this range. Because it is assumed that the annualized volatility of the price of the mineral
TABLE 1: The statistic table of the annualized volatility.

\begin{tabular}{lcc}
\hline Range $(\%)$ & Frequency & Probability \\
\hline$[0,10)$ & $a_{1}$ & $a_{1} / n$ \\
{$[10,20)$} & $a_{2}$ & $a_{2} / n$ \\
{$[20,30)$} & $a_{3}$ & $a_{3} / n$ \\
{$[30,40)$} & $a_{4}$ & $a_{4} / n$ \\
{$[40,50)$} & $a_{5}$ & $a_{5} / n$ \\
{$[50,60)$} & $a_{6}$ & $a_{6} / n$ \\
{$[60,70)$} & $a_{7}$ & $a_{7} / n$ \\
\hline
\end{tabular}

Note. $a_{1}+a_{2}+a_{3}+a_{4}+a_{5}+a_{6}+a_{7}=n$.

TABLE 2: The distribution series of annualized volatility of spot copper price.

\begin{tabular}{lc}
\hline Annualized volatility (\%) & Probability \\
\hline 5 & $a_{1} / n$ \\
15 & $a_{2} / n$ \\
25 & $a_{3} / n$ \\
35 & $a_{4} / n$ \\
45 & $a_{5} / n$ \\
55 & $a_{6} / n$ \\
65 & $a_{7} / n$ \\
\hline
\end{tabular}

product follows a multinomial distribution, the annualized volatility can only take a finite number of values. Therefore, in this study, the midpoint value of the annualized volatility in each group's statistical range is selected as the representative value of the group. Table 2 lists the distribution series of the annualized volatility of the spot price of copper used as an example in the previous paragraph.

3.3. Convenience Yield. Convenience yield can be viewed as the potential yield from the carrying of a stock. Considering the time loss and transportation cost resulting from the transportation of a commodity, convenience yield can be viewed as the value of the yield generated by filling the temporary local shortage of the commodity with the stocked commodity. Convenience yield can also be viewed as the yield generated by promptly providing raw materials to maintain production.

Convenience yield has the following characteristics: when the stock of a commodity is relatively low, its spot price will increase because of the short supply and the convenience yield will also be at a correspondingly high level. In this case, the yield from carrying a stock of the commodity will be higher. When there is a surplus stock of a commodity, its spot price is relatively low and the convenience yield is low as well. In other words, convenience yield is negatively correlated to the stock level and positively correlated to the spot price.

The process of calculating the convenience yield based on the relationship between the futures price and the spot price is as follows:

$$
F_{t}=S_{t} e^{\left(r-\delta_{t}\right) T^{\prime}}
$$


By rearranging the terms, we have

$$
\delta_{t}=r-\frac{1}{T^{\prime}} \ln \frac{F_{t}}{S_{t}},
$$

where $F_{t}$ represents the price of the mineral product of a certain futures contract at time $t$; $S_{t}$ represents the spot price of the mineral product at time $t ; r$ represents the risk-free interest rate; $\delta_{t}$ represents the convenience yield at time $t$; and $T^{\prime}$ represents the remaining time before the mining concession expires (unit: years).

Gibson et al. discuss the time-series nature of the convenience yield of crude oil futures, concluding that the convenience yield of crude oil futures exhibits meanreversion characteristics [22]. Therefore, when used in model calculation, the mean convenience yield within a certain period of time can be selected as the representative value for calculation. The mean convenience yield, $\bar{\delta}$, within $n_{d}$ number of days is calculated:

$$
\bar{\delta}=\frac{1}{n_{d}} \sum_{t=1}^{n_{d}} \delta_{t} .
$$

After considering the convenience yield factor, the riskfree interest rate should be adjusted correspondingly. If the risk-free interest rate is $r$ and the mean convenience yield is $\bar{\delta}$, then the adjusted risk-free interest rate, $r^{\prime}$, is

$$
r^{\prime}=r-\bar{\delta}
$$

3.4. Combined Multinomial Pricing Model. Numerous researchers have realized the deficiency of the constant volatility assumption. For example, in addition to determining 22\% as a suitable annualized volatility value, Smit performs a calculation with annualized volatility values of $15 \%$ and $30 \%$ as a reference [7]. However, Smit's method is problematic when used in practice because it is very difficult for a mining company to predict the future value of the volatility of the price of mineral products. In contrast, under the assumption that the annualized volatility of the price of mineral products follows a multinomial distribution, that means the annualized volatility values of the price of the mineral product of the previous years are mutually independent. Therefore, the aforementioned problem can be solved by combining multiple binomial pricing models into a multinomial pricing model.

Here, we present an example of conducting a grouped statistical analysis of the annualized volatility of the price of a mineral product in $q$ number of years. The number of the group is $l$. If the probability for the annualized volatility belonging to each group is $P_{i}(1 \leq i \leq l)$, the representative value of the annualized volatility of each group is $\sigma_{i}$, the risk-free interest rate is $r$, and the mean convenience yield is $\bar{\delta}$. Each representative value of the annualized volatility is calculated using a binomial pricing model. Then, we have

$$
\begin{aligned}
b_{2 i-1} & =e^{\sigma_{i}}, \\
b_{2 i} & =e^{-\sigma_{i}} \\
p_{2 i-1}^{\prime} & =\frac{e^{(r-\bar{\delta}) T}-b_{2 i}}{b_{2 i-1}-b_{2 i}}, \\
p_{2 i}^{\prime} & =1-\frac{e^{(r-\bar{\delta}) T}-b_{2 i}}{b_{2 i-1}-b_{2 i}},
\end{aligned}
$$

where $b_{2 i-1}, b_{2 i}, p_{2 i-1}^{\prime}$, and $p_{2 i}^{\prime}$ represent either the upstream or downstream multipliers of the value of the mine and the corresponding probabilities calculated using a binomial pricing model when the annualized volatility is $\sigma_{i}$. To combine these binomial pricing models, it is necessary to multiply the probability of the upstream or downstream multiplier of the value of the mine in each binomial pricing model with the probability of corresponding annualized volatility. Then, we have

$$
\begin{aligned}
p_{2 i-1} & =\frac{e^{(r-\bar{\delta}) T}-b_{2 i}}{b_{2 i-1}-b_{2 i}} P_{i}, \\
p_{2 i} & =\left(1-\frac{e^{(r-\bar{\delta}) T}-b_{2 i}}{b_{2 i-1}-b_{2 i}}\right) P_{i},
\end{aligned}
$$

where $p_{2 i-1}$ and $p_{2 i}$ represent the probabilities used in the model combined by the aforementioned binomial pricing models when the upstream and downstream multipliers are $b_{2 i-1}$ and $b_{2 i}$.

Based on (12) and (14), the multistep multinomial pricing model mentioned in Section 2.2 can be adjusted. If $f_{0}$ represents the price of the mining concession, a combined multinomial pricing model is then obtained:

$$
\begin{aligned}
& f_{b_{1}{ }^{k_{1}} b_{2}{ }^{k_{2} \ldots b_{m}}{ }^{k_{m}}}=\max \left(0, S \prod_{j=1}^{m} b_{j}^{k_{j}}-X\right) \\
& (1 \leq j \leq 2 l, j \in \mathrm{N}) \\
& f_{0}=e^{-(r-\bar{\delta}) T}\left(\sum_{k_{1}+k_{2}+\cdots+k_{m}=n} \frac{n !}{\prod_{i=1}^{m} k_{i} !} \prod_{j=1}^{m} p_{j}^{k_{j}}\right.
\end{aligned}
$$

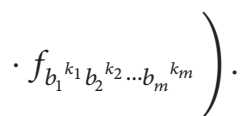

Figure 1 shows the multinomial tree diagram of the combined multinomial pricing model.

\section{Empirical Study}

With the price of the mining concession of a copper mine in China as the study object, this study performs an empirical analysis of the combined multinomial pricing model when assuming that the mine production is conducted continuously. 

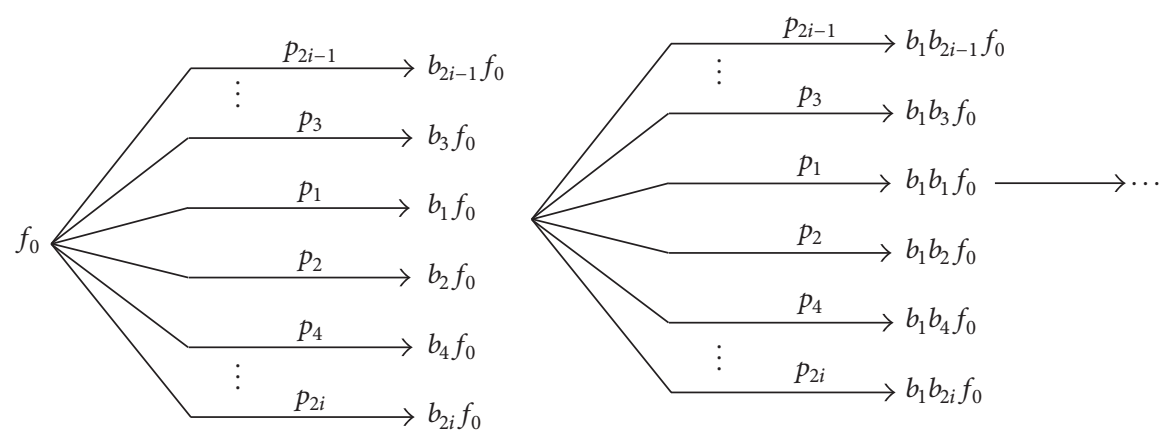

FIGURE 1: The multinomial tree diagram of the combined multinomial pricing model.

4.1. Data Sources and Processing. The mining concession information used in this study originated from the Ministry of Land and Resources of the People's Republic of China. The transfer of the ownership of the mining concession of a copper mine was offered and a public announcement about the offer was made. The mine had 211,200 tons of copper ore and 2000.22 tons of copper remaining, with an annual production capacity of 30,000 tons/year. Thus, the mine had a service life of $T=211200 / 30000=7.04 \approx 7$ years. $\mathrm{A}$ copper mining company intended to purchase the mining concession of the copper mine. The full cost of operating the mine was 29,000 yuan/ton.

The copper futures data originated from the Shanghai Futures Exchange. The spot data on the copper were obtained from the Shanghai Metal Exchange Market. The daily morning spot prices of copper were selected as the spot price of copper. The daily settlement prices of copper futures were selected as the futures price of copper. The dates of the samples span from January 1, 2007, to December 31, 2015. After removing the number of nontrading days caused by holidays, there are 2,187 samples. When calculating the price of the mining concession, the first trading day in 2016 (January 4, 2016) is used as the initial time. The spot price of copper on January 4, 2016, was 36,250 yuan/ton. In addition, the number of spot copper trading days in China is generally fewer than 250 days per year. Based on the statistical analysis of the number of spot trading days between 2007 and 2015, the number of trading days in each year is set to 243 days for the empirical study.

There are multiple copper futures contracts on the futures market at the same time and there are differences in the settlement prices of most of the contracts on the same day. In addition, a futures contract has an expiration date after which the futures are no longer listed for trading. Therefore, futures prices are discontinuous. To construct continuous futures prices, the settlement price of the contract with the largest trading volume in each month is selected as the futures price of the month to construct a continuous contract. For copper futures, the futures price of copper in January 2015 was the settlement price of the futures contract that expired in April 2015 (the contact with the largest trading volume in January 2015). Because mining is a high-risk industry, it is unsuitable to directly use either the deposit interest rate or the treasury bond interest rate as the risk-free interest rate. Therefore, this

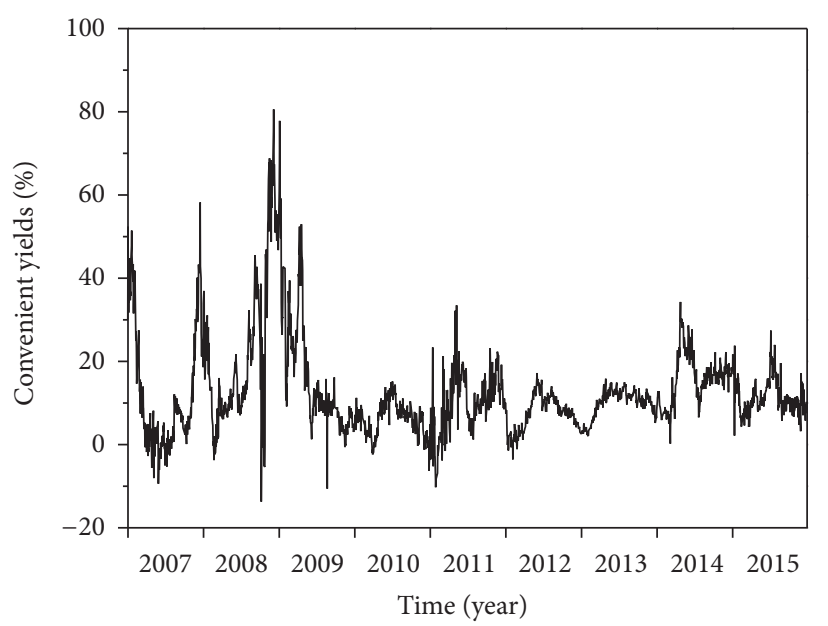

Figure 2: The daily convenience yield of copper between 2007 and 2015.

study selects $8 \%$ as the long-term risk-free interest rate when calculating the price of the mining concession based on the requirements for calculating mining concessions established in A Guide for Evaluation of Mining Concessions [23].

4.2. Model Calculation. Based on the data acquired, the daily convenience yield of copper can be calculated using (9) and is shown in Figure 2.

Figure 3 shows the trend of the futures and spot prices of copper between 2007 and 2015.

It can be observed from Figure 2 that the convenience yield essentially fluctuated around $10 \%$, except that there were relatively large fluctuations in the convenience yield of copper futures between 2007 and 2009. It can be observed from Figure 3 that there were significant fluctuations in the trend of the price of copper between 2007 and 2009. Between 2007 and mid-2008, the price of copper fluctuated at a high level. During this time, copper mining companies showed a strong will to engage in production and the convenience yield essentially fluctuated below $40 \%$. However, beginning in November 2008, the price of copper dropped significantly. Because the copper mining companies' reluctance to sell resulted in a reduced quantity of copper being placed on the market, the convenience yield increased above $50 \%$. In 


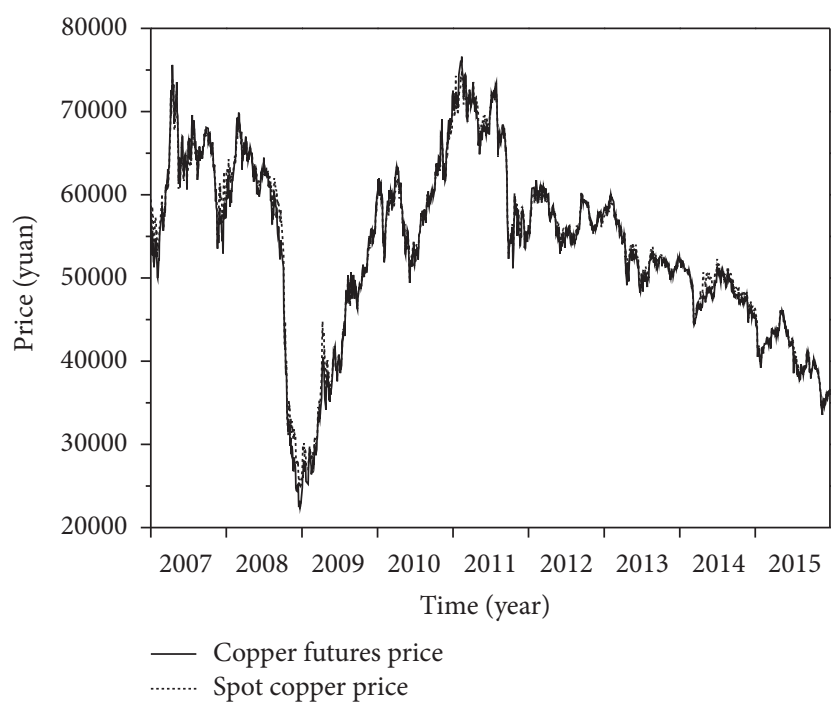

Figure 3: The trend of the futures and spot prices of copper between 2007 and 2015.

TABLE 3: The annualized volatility values of spot copper price in China from 2007 to 2015.

\begin{tabular}{lc}
\hline Year & Annualized volatility (\%) \\
\hline 2007 & 28.07 \\
2008 & 33.50 \\
2009 & 33.49 \\
2010 & 20.87 \\
2011 & 22.87 \\
2012 & 11.24 \\
2013 & 13.74 \\
2014 & 13.29 \\
2015 & 18.58 \\
\hline
\end{tabular}

order to recover rapidly from the world economic crisis, the Chinese government implemented a four-trillion-yuan stimulus plan. The level of inflation then significantly increased and the price of mineral products quickly demonstrated a transition from a bear market to a bull market. In 2009, as the futures price of copper gradually increased, investors were optimistic about a rise in the price of copper. As a result, the mining companies were willing to produce more copper. Consequently, there was no longer a shortage of copper, and thus the convenience yield decreased again and fluctuated around 5\%. The price of copper dropped again beginning in June 2011, but this drop was not as sharp as in year 2008. Therefore, the convenience yield increased nonsignificantly and fluctuated around $10 \%$.

Based on (10), $\bar{\delta}$ is calculated $(\bar{\delta}=10 \%)$.

This study assumes that the value of the mine equals the product of the price of the mineral product and the reserve of the mineral product. Based on the existing spot price data, the annualized volatility of the spot price of copper between 2007 and 2015 is calculated. Table 3 lists the calculation results.
TABLE 4: The statistic table of annualized volatility of spot copper price in China from 2007 to 2015.

\begin{tabular}{lccc}
\hline Range (\%) & {$[0,10)$} & {$[10,20)$} & {$[20,30)$} \\
\hline Frequency & 4 & 3 & 2 \\
Probability & $4 / 9$ & $1 / 3$ & $2 / 9$ \\
\hline
\end{tabular}

TABLE 5: The multiples and their corresponding probabilities of representative value of annualized volatility.

\begin{tabular}{lccc}
\hline $\begin{array}{l}\text { Representative value of annualized } \\
\text { volatility (\%) }\end{array}$ & UM/DM & Probability (\%) \\
\hline \multirow{2}{*}{15} & UM & 1.16 & 17.64 \\
& DM & 0.86 & 26.81 \\
25 & UM & 1.28 & 13.29 \\
& DM & 0.78 & 20.05 \\
35 & UM & 1.42 & 8.57 \\
& DM & 0.70 & 13.65 \\
\hline
\end{tabular}

Note. UM refers to the upstream multiplier of the price of mineral products. DM refers to the downstream multiplier of the price of mineral products.

The nine aforementioned annualized volatility values can be divided into three groups. The statistical range and the probability of each of the groups are listed in Table 4.

Based on the description in Section 3.1, 15\%, 25\%, and $35 \%$ can be selected as each group's representative values. Based on (12) and (14), the probabilities and the multipliers of the value of the mine required for calculating the combined multinomial pricing model can be obtained (the long-term risk-free interest rate is set to $8 \%$ ). Table 5 lists the calculation results.

Based on the data listed in Table 5, the price of the mining concession can be obtained using the combined multinomial model based on (15) (20.48 million yuan).

\section{Discussion and Further Analysis}

5.1. Comparison of Discounted Cash Flow (DCF) Model and Combined Multinomial Pricing Model. Nowadays, most countries and companies use DCF model to price mining concessions. DCF model is easy to use and its result is accurate and relatively objective.

DCF model is a method using the concepts of the time value of money. When using DCF model to price mining concessions, all future cash flows are estimated and discounted by using cost of capital to give their present values. The sum of all future cash flows is the net present value, which is taken as the price of mining concessions. The calculation process of DCF model is as follows:

$$
V_{\mathrm{MC}}=\sum_{i=1}^{n} \frac{\mathrm{CF}_{i}}{(1+r)^{i}}=\sum_{i=1}^{n} \frac{(\mathrm{CI}-\mathrm{CO})_{i}}{(1+r)^{i}}
$$

where $V_{\mathrm{MC}}$ represents the value of mining concession; CF represents the annual cash flow; CI represents the annual cash inflow; $\mathrm{CO}$ represents the annual cash outflow; $r$ represents the discount rate; $i$ represents the number of years after 
TABLE 6: The annual net cash flow after purchasing the mining concession.

\begin{tabular}{lc}
\hline Year & Net cash flow (thousand yuan) \\
\hline 1 & -3623.20 \\
2 & -321.60 \\
3 & 1418.20 \\
4 & 1418.20 \\
5 & 1418.20 \\
6 & 1418.20 \\
7 & 1418.20 \\
\hline
\end{tabular}

purchasing the mining concession; $n$ represents the time to expiration of the mining concession.

If the DCF model is used to price mineral concessions, the discount rate ought to be determined first. When pricing mining concessions in China, the discount rate is $8 \%$ according to A Guide for Evaluation of Mining Concessions. The mine had a service life of 7 years. Table 6 lists the annual net cash flow after purchasing the mining concession.

Based on the data listed in Table 6 and (16), the price of the mining concession is calculated (1.22 million yuan). We can find out that the price calculated by DCF model is significantly lower than the price calculated by combined multinomial pricing model (20.48 million yuan). The reason is that the DCF model does not take into consideration the uncertainty of the fluctuation of the price of mineral products and the flexibility of business strategy.

\subsection{Comparison of Traditional Binomial Pricing Model and} Combined Multinomial Pricing Model. In the combined multinomial pricing model, we take into consideration the high and low annualized volatility values in one model. This is different from the traditional binomial pricing model. If the traditional binomial pricing model is used to calculate the study object of this research, a series of values of constant annualized volatility can be selected. In addition, the results can be compared with the calculation results obtained using the combined multinomial pricing model. Based on the annualized volatility data for 2007-2015 listed in Table 3, we can select $15 \%, 20 \%, 25 \%$, and $30 \%$ as the constant annualized volatility of the spot price of copper and price the mining concession of the copper mine, respectively, using the binomial pricing model. Table 7 lists the calculation results obtained when we take the convenience yield into consideration.

It can be observed from Table 7 that, under the constant annualized volatility assumption, the price of the mining concession increased with increasing annualized volatility. Based on the study of Figuerola-Ferretti and Gilbert, if we take into consideration the variation of the price of copper on the London Metal Exchange between 1982 and 2005, it can be seen that, for most years, the annualized volatility of the price of copper was between $20 \%$ and 25\% [21]. The statistical data of the annualized volatility of the spot price of copper listed in Table 3 also essentially conforms to the aforementioned characteristic. The mean annualized volatility of the nine years is less than $25 \%$; however, the
TABLE 7: The comparison of results by using binomial tree model with constant annualized volatility and the model from this paper.

\begin{tabular}{lcc}
\hline $\begin{array}{l}\text { Annualized } \\
\text { volatility }\end{array}$ & $\begin{array}{c}\text { The price of the concession } \\
\text { (million yuan) }\end{array}$ & $\begin{array}{c}\text { Calculation } \\
\text { model }\end{array}$ \\
\hline $15 \%$ & 13.83 & TBPM \\
$20 \%$ & 16.85 & TBPM \\
$25 \%$ & 20.20 & TBPM \\
$30 \%$ & 23.83 & TBPM \\
Multi & 20.48 & CMPM \\
\hline
\end{tabular}

Note. Here, "Multi" refers to using multiple annualized volatilities to calculate the price of the concession. TBPM refers to traditional binomial pricing model. CMPM refers to combined multinomial pricing model.

calculation results obtained using the model proposed in this study are slightly higher than the calculation results obtained using $25 \%$ as the constant annualized volatility. This is because the data that could be acquired on the spot price of copper of China were limited and thus only the annualized volatility data of nine years are statistically analyzed; consequently, there is a greater probability that the annualized volatility will fall within the $30 \%-40 \%$ interval. If more statistical data can be acquired (e.g., more than 20 years of annualized volatility data), the pricing of a mining concession using the combined multinomial pricing model will be more accurate.

\section{Conclusion}

This study proposes a combined multinomial pricing model based on the assumption that the annualized volatility of the price of a mineral product follows a multinomial distribution. The distribution series of the annualized volatility of the price of the mineral product is obtained through grouped statistical analysis. The midpoint value of each group's statistical range is used as the representative values and possible value of the annualized volatility. Calculation is then performed on each of these representative values using a binomial pricing model. The probabilities and the multipliers calculated using different values of the annualized volatility can thus be obtained. Because we assume that the annualized volatility of the price of mineral products follows a multinomial distribution, the annualized volatility values of the price of the mineral product of the previous years are mutually independent. Therefore, the aforementioned multiple binomial pricing models can be combined into a multinomial pricing model based on the probability corresponding to the respective annualized volatility, which is then used to price the mining concession.

This study uses the proposed pricing model to price the mining concession of a copper mine in China. The empirical study demonstrates that when used to price the mining concession, the combined multinomial pricing model provides a more comprehensive consideration of the changing annualized volatility of the price of the mineral product than the traditional decision tree methods by considering the high and low annualized volatility simultaneously. Therefore, 
pricing mining concessions using the proposed model is more reasonable.

\section{Competing Interests}

The authors declare that there are no competing interests regarding the publication of this paper.

\section{Acknowledgments}

This research was supported by China Geological Survey (Grant no. DD20160073). The research was also supported by the Lab of Resources and Environmental Management which is in China University of Geosciences, Beijing.

\section{References}

[1] J. C. Cox, S. A. Ross, and M. Rubinstein, "Option pricing: a simplified approach," Journal of Financial Economics, vol. 7, no. 3, pp. 229-263, 1979.

[2] G. Tessitore and J. Zabczyk, "Pricing options for multinomial models," Bulletin of the Polish Academy of Sciences Mathematics, vol. 44, no. 3, pp. 363-380, 1996.

[3] Y.-P. Chang, M.-C. Hung, and Y.-C. Ko, "A multinomial tree model for pricing credit default swap options," Computational Statistics, vol. 26, no. 1, pp. 95-120, 2011.

[4] C. Ogutu, K. Lundengård, S. Silvestrov et al., "Pricing Asian options using moment matching on a multinomial lattice," American Institute of Physics Conference Series, vol. 1637, no. 1, pp. 759-765, 2014.

[5] H. Smit, "Investment analysis of offshore concessions in The Netherlands," Financial Management, vol. 26, no. 2, pp. 5-17, 1997.

[6] Q.-H. Gu, Q. Wu, and C.-W. Lu, "Trinomial tree model of the real options approach used in mining investment price forecast and analysis," Journal of Coal Science and Engineering, vol. 19, no. 4, pp. 573-577, 2013.

[7] S. H. Ting, C.-O. Ewald, and W.-K. Wang, "On the investmentuncertainty relationship in a real option model with stochastic volatility," Mathematical Social Sciences, vol. 66, no. 1, pp. 22-32, 2013.

[8] B. Huang, J. Cao, and H. Chung, "Strategic real options with stochastic volatility in a duopoly model," Chaos, Solitons \& Fractals, vol. 58, no. 1, pp. 40-51, 2014.

[9] R. Liesenfeld and R. C. Jung, "Stochastic volatility models: conditional normality versus heavy-tailed distributions," Journal of Applied Econometrics, vol. 15, no. 2, pp. 137-160, 2000.

[10] T. G. Andersen, T. Bollerslev, F. X. Diebold, and P. Labys, "The distribution of realized exchange rate volatility," Journal of the American Statistical Association, vol. 96, no. 453, pp. 42-55, 2001.

[11] T. G. Andersen, T. Bollerslev, F. X. Diebold, and H. Ebens, "The distribution of realized stock return volatility," Journal of Financial Economics, vol. 61, no. 1, pp. 43-76, 2001.

[12] D. B. Madan, F. Milne, and H. Shefrin, "The multinomial option pricing model and its Brownian and Poisson limits," Review of Financial Studies, vol. 2, no. 2, pp. 251-265, 1989.

[13] I. Florescu and F. G. Viens, "Stochastic volatility: option pricing using a multinomial recombining tree," Applied Mathematical Finance, vol. 15, no. 2, pp. 151-181, 2008.
[14] N. Kaldor, "A symposium on the theory of the forward market: I. A note on the theory of the forward market," The Review of Economic Studies, vol. 7, no. 3, pp. 196-201, 1940.

[15] W. T. Lin and C.-W. Duan, "Oil convenience yields estimated under demand/supply shock," Review of Quantitative Finance and Accounting, vol. 28, no. 2, pp. 203-225, 2007.

[16] C. Stepanek, M. Walter, and A. Rathgeber, "Is the convenience yield a good indicator of a commodity's supply risk?" Resources Policy, vol. 38, no. 3, pp. 395-405, 2013.

[17] J. C. Cox and M. Rubinstein, Options Markets, Prentice-Hall, Englewood Cliffs, NJ, USA, 1985.

[18] B. Rockenbach, "The behavioral relevance of mental accounting for the pricing of financial options," Journal of Economic Behavior \& Organization, vol. 53, no. 4, pp. 513-527, 2004.

[19] Z. L. Yan, Multinomial option pricing model based on behavioral finance [M.S. dissertation], Huazhong University of Science \& Technology, 2011 (Chinese).

[20] J. C. Hull, Options, Futures, and Other Derivatives, PrenticeHall, Englewood Cliffs, NJ, USA, 2014.

[21] I. Figuerola-Ferretti and C. L. Gilbert, "Commonality in the LME aluminum and copper volatility processes through a figarch lens," Journal of Futures Markets, vol. 28, no. 10, pp. 935962, 2008.

[22] R. Gibson, E. S. Schwartz, and D. Lund, "Valuation of long term oil-linked assets," Stochastic Models and Option Values, vol. 73, article 101, 1991.

[23] The Writing Group of A Guide for Evaluation of Mining Concessions, A Guide for Evaluation of Mining Concessions, China Land Press, Beijing, China, 2004 (Chinese). 


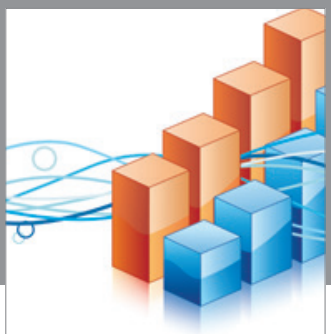

Advances in

Operations Research

vatem alat4

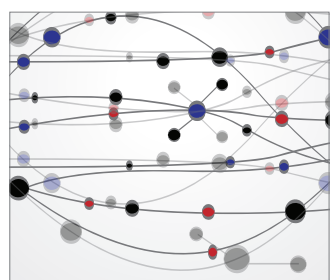

\section{The Scientific} World Journal
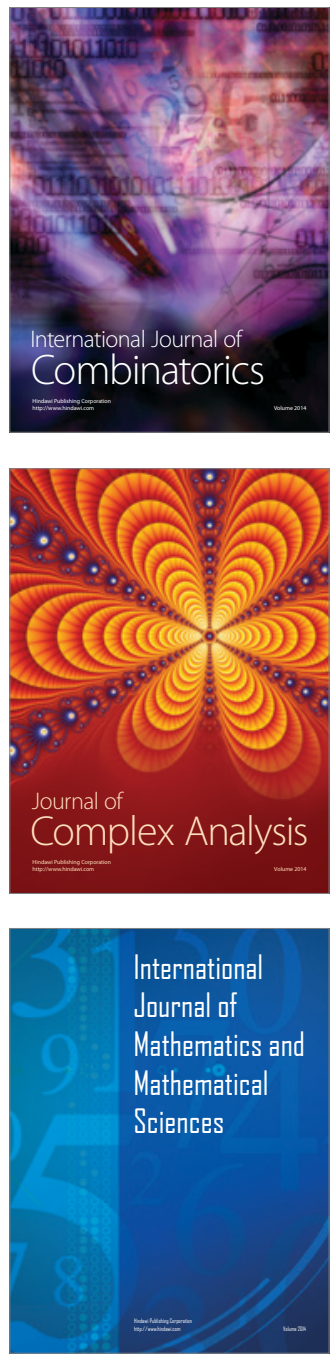
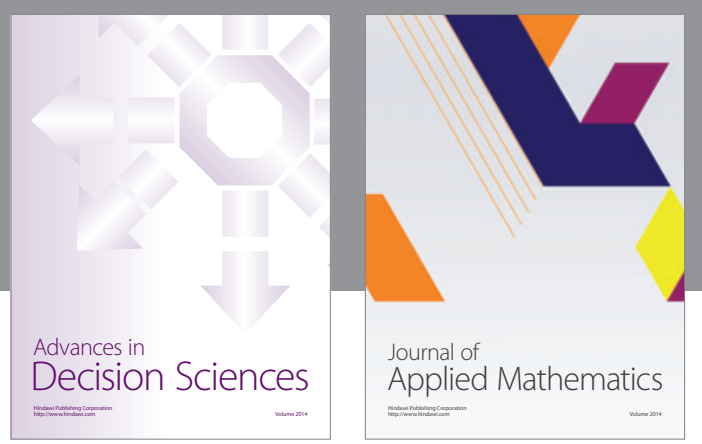

Algebra

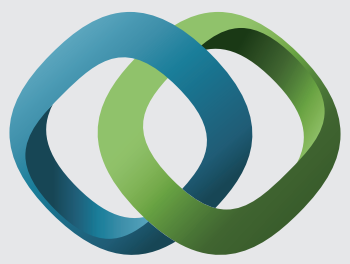

\section{Hindawi}

Submit your manuscripts at

https://www.hindawi.com
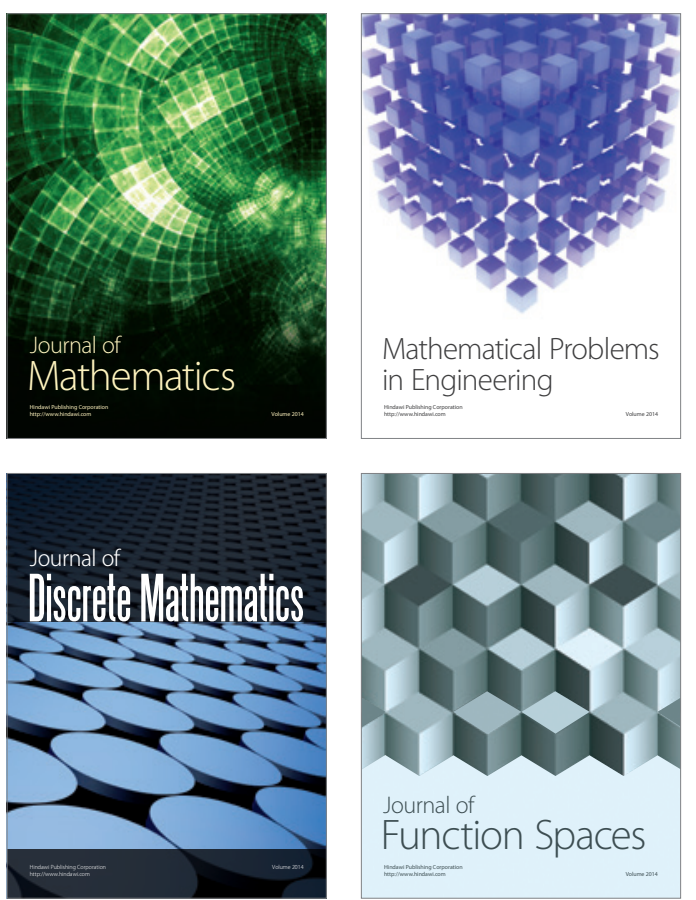

Mathematical Problems in Engineering
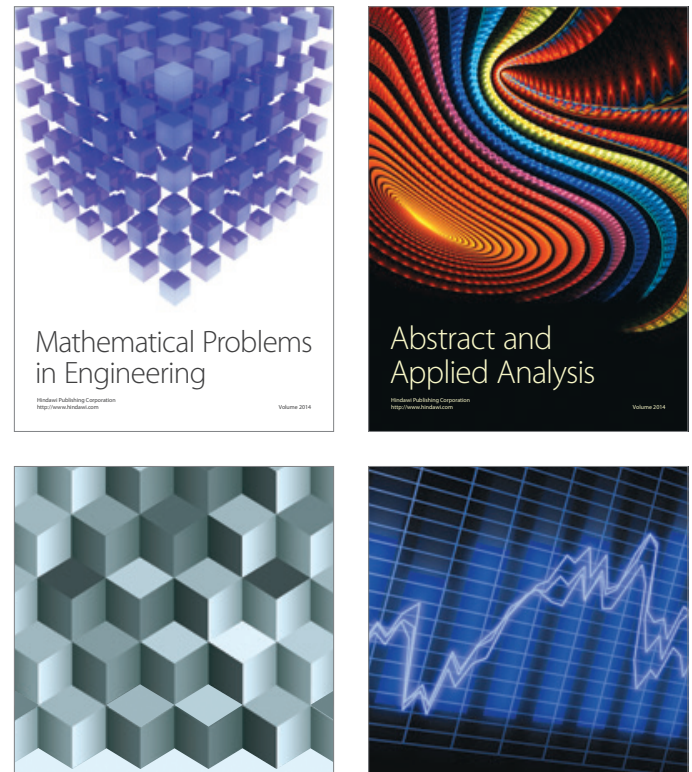

Journal of

Function Spaces

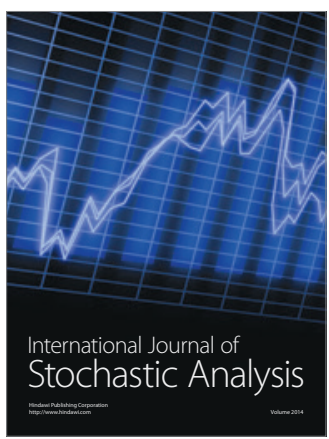

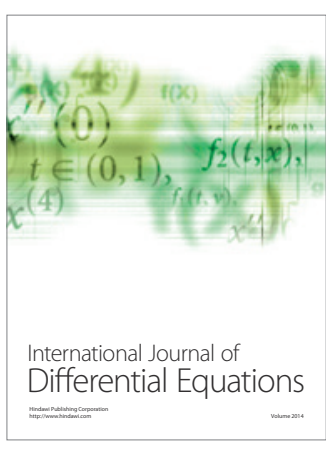
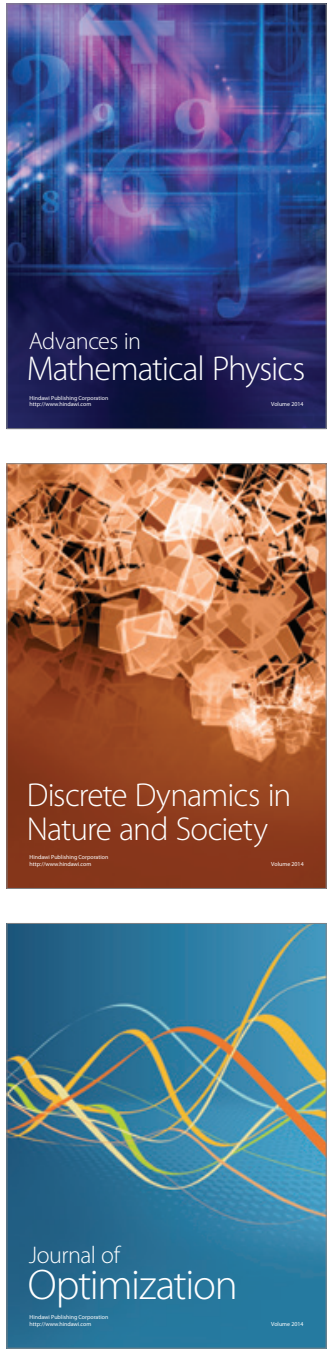